\title{
Resistive Monolithic Q-Band HEMT Mixer for MVDS Applications
}

\author{
B. Aja ${ }^{*}$, M.L. de la Fuente ${ }^{*}$, J.A. García ${ }^{* *}$, J.P. Pascual ${ }^{*}$, E. Artal ${ }^{*}$ \\ * Dpto. Ing. de Comunicaciones. Universidad de Cantabria. SPAIN \\ beatriz@dicom.unican.es \\ **At present: TTI Norte. SPAIN \\ jagarcia@ttinorte.es
}

\begin{abstract}
This paper describes the design of a resistive monolithic Q-band HEMT mixer for optimum conversion loss and IMD performance. Transistor two-sided harmonic measurements across $V_{d s}$ and $V_{\text {gs }}$ revealed the presence of IMD sweet spots that were used to optimize the conversion loss and IMD behavior of the mixer. Minimum conversion loss of $10 \mathrm{~dB}$ was measured in the 40.8-49 $\mathrm{GHz} \mathrm{RF}$ frequency band, showing a reasonable agreement with simulation results. Mixer single-tone IMD was measured and simulated. The minimum output level at $3 F_{\mathrm{IF}}$ was less than $-102 \mathrm{dBm}$ for an $\mathrm{RF}$ input level of $-10 \mathrm{dBm}$ and for a bias point near the predicted sweet spot.
\end{abstract}

\section{INTRODUCCION}

The future broadband wireless systems will use the 28 or $42 \mathrm{GHz}$ millimeter wave bands. In Europe, these systems called MVDS (Microwave Video Distribution System) will be located in the 40.5-42.5 $\mathrm{GHz}$ frequency band. Because of the novelty of these services, scarce products have been developed for these purposes, which makes interesting the design of circuits in these frequency bands. The monolithic mixer presented in this paper makes up of the customer receiver, where the input frequency signals lie in the Qband and the output frequency (IF) range covers a wide bandwidth $(0.4 \mathrm{GHz}-9 \mathrm{GHz})$ which includes the commercial product frequency range $(950-2150 \mathrm{MHz})$.

\section{DESIGN}

Good conversion efficiency, low noise and good IMD performance are the main goals to be fulfilled by a receiver. For that reason, a single-ended resistive HEMT mixer was considered more suitable [1], [2].

In order to get good IMD performance, a specific technique for IMD characterization of MESFETs and HEMTs proposed in [3] was used. For a typical FET transistor, two-sided harmonic measurements [4],[5], across $\mathrm{V}_{\mathrm{ds}}$ and $\mathrm{V}_{\mathrm{gs}}$ revealed the presence of drain bias induced IMD sweet spots and minimum conversion loss gate bias. The minimum IMD points across $\mathrm{V}_{\mathrm{ds}}$ and $\mathrm{V}_{\mathrm{gs}}$ were found for a constant value of $\mathrm{V}_{\mathrm{gd}}$ and equal to the pinch-off value ( $\cong-0.6$ volts). The minimum conversion loss can be predicted with the most non-linear zone of $\mathrm{G}_{\mathrm{ds}}\left(\partial I_{d s} / \partial V_{d s}\right)$, which corresponds to a maximum of $\mathrm{G}_{\mathrm{md}}\left(\partial^{2} I_{d s} / \partial V_{d s} V_{g s}\right)$. This point was found a little above the pinch-off value: -0.4 volts. Resistive mixers use to work under cold bias $\left(\mathrm{V}_{\mathrm{ds}}=0\right.$ volts $)$, but the best in-band linearity performance has been found for a slightly positive $\mathrm{V}_{\mathrm{ds}}$. For that reason, the drain voltage can be modified to get the best performance.

A LO amplifier was integrated in the same chip to use a lower LO power level. A common-source transistor makes up this amplifier. A diplexer was integrated in the chip to apply the RF signal and to extract the IF signal. The circuit was designed using the MDS (Hewlett Packard) software. Since lumpedelement models do not fit in an accurate way at millimetre-wave frequencies (above $26 \mathrm{GHz}$ ), an electromagnetic simulator was used to design the matching networks and the diplexer. Coupling between closed structures is also taken into account. The amplifier and mixer transistors have a total gate width of 300 (6x50) $\mu \mathrm{m}$ each one.

The chip was fabricated in Philips Microwave Limeil, using the ED02AH process, which permits 0.2 $\mu \mathrm{m}$ gate length HEMTs. Fig. 1 shows a photograph of the mixer. The chip size is $3 \mathrm{~mm}^{2}$, but two transistors were included to test them.

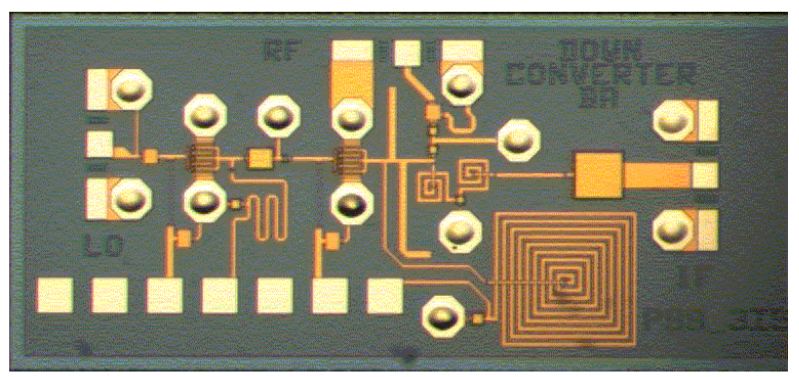

Fig. 1: Photograph of the chip 


\section{MEASUREMENTS}

The circuit was measured on wafer using a coplanar-wave station. Fig. 2 presents the measured conversion loss across $\mathrm{V}_{\mathrm{gs}}$ for a constant $\mathrm{V}_{\mathrm{ds}}$ of 0 volts, and Fig. 3 shows the conversion loss in the RF frequency band for the optimum bias point with a LO input power of $5 \mathrm{dBm}$.

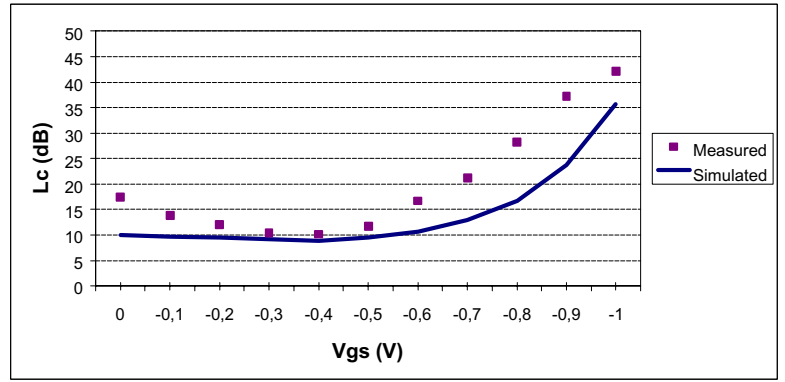

Fig. 2: Conversion Loss vs gate source voltage

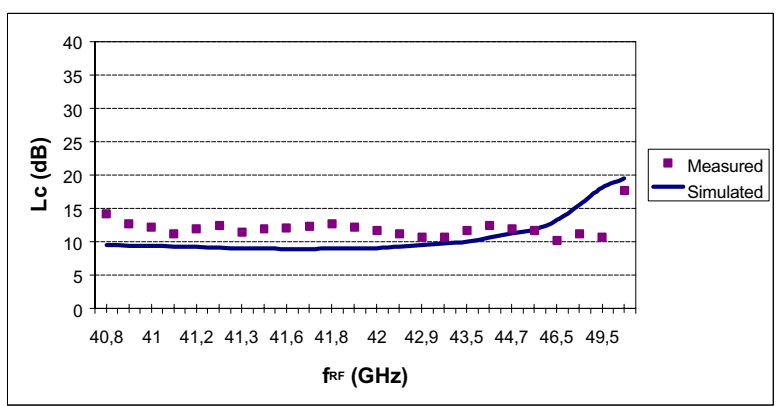

Fig. 3: Conversion Loss vs RF frequency

Conversion loss across the LO power level was also measured as can be seen in Fig. 4. Simulated results were included in these figures, showing a reasonable agreement.

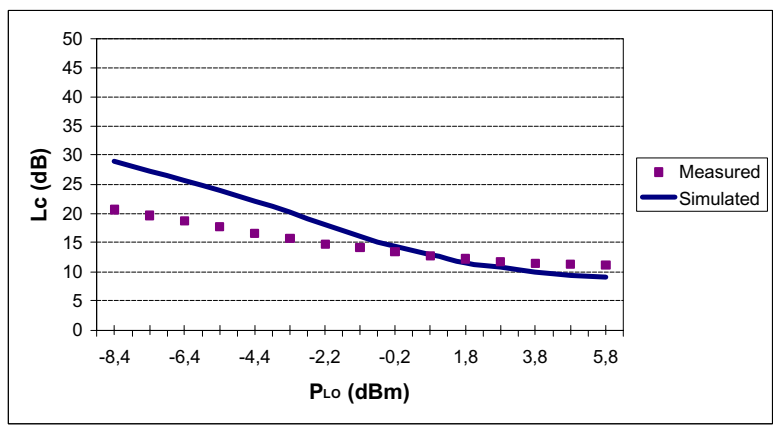

Fig. 4: Conversion Loss vs LO Power

Single-tone IM levels were measured. Fig.5 shows the relative output level at $3 \mathrm{f}_{\mathrm{IF}}$ across $\mathrm{V}_{\mathrm{ds}}$ for a $0 \mathrm{dBm}$ LO power. There is a minimum level for $3 \mathrm{f}_{\mathrm{IF}}$ near $\mathrm{V}_{\mathrm{ds}}=$ 0.17 volts, which agrees quite well with the best IMD predicted performance $\left(\mathrm{V}_{\mathrm{gd}}=0.57\right.$ volts $)$. For a higher LO power level, the $\mathrm{V}_{\mathrm{ds}}$ value for minimum IMD is slightly greater, which can be due to the high LO power [6]. Indeed, the minimum output level for $3 \mathrm{f}_{\mathrm{IF}}$ occurs for $\mathrm{V}_{\mathrm{ds}}=0.6$ volts with a $5 \mathrm{dBm}$ LO power, as can be seen in Fig.6.

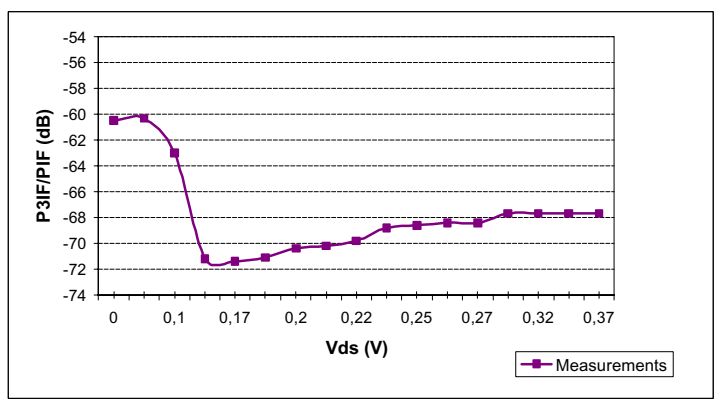

Fig. 5: Relative output level at $3 \mathrm{f}_{\mathrm{IF}}$ across $\mathrm{V}_{\mathrm{ds}}$ for a $0 \mathrm{dBm} \mathrm{LO}$ power

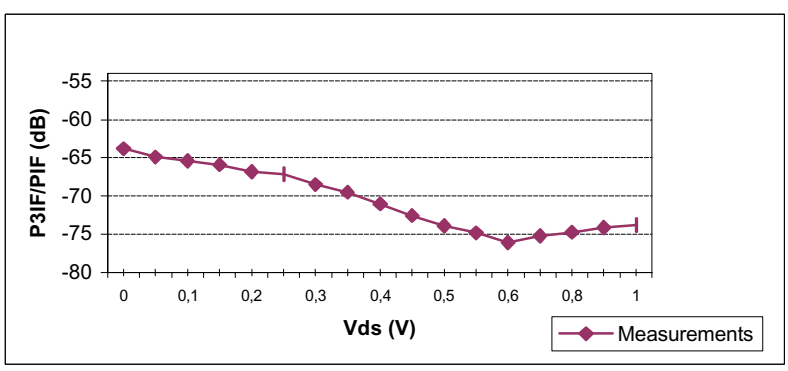

Fig. 6: Relative output level at $3 \mathrm{f}_{\mathrm{IF}}$ across $\mathrm{V}_{\mathrm{ds}}$ for a $5 \mathrm{dBm} \mathrm{LO}$ power

$\mathrm{LO} / \mathrm{RF}$ and $\mathrm{LO} / \mathrm{IF}$ measured isolations were better than $40 \mathrm{~dB}$ in the whole frequency band. RF return loss was measured, being better than $9 \mathrm{~dB}$, as can be seen in Fig. 7. IF return loss was added in the same figure.

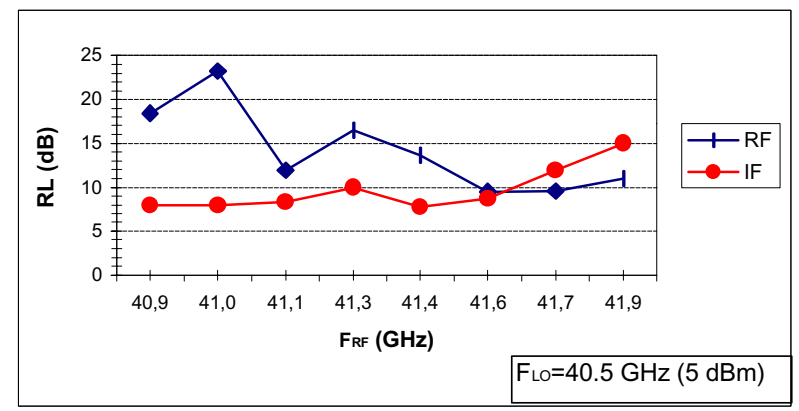

Fig. 7: IF and RF return loss

More than $9 \mathrm{~dB}$ LO return loss was measured for 0 $\mathrm{dBm}$ LO power. 
The optimization of conversion loss and IMD behavior with proper $\mathrm{V}_{\mathrm{gs}}$ and $\mathrm{V}_{\mathrm{ds}}$ bias voltages has also been extended to the case of a more realistic multitone $\mathrm{RF}$ excitation. The spectral regrowth reduction with a slight $\mathrm{V}_{\mathrm{ds}}$ value has been obtained for a digital QPSK signal, the modulation format to employ in the referred MVDS system. Adjacent-channel power ratio (ACPR) testing is commonly used in the wireless communications industry to characterize the distortion performance of these systems. For this test, the mixer has worked as upconverter because a Q-band QPSK signal was not available. We believe the results are equivalents to those when the mixer works as a downconverter. A vector signal analyzer (HP 89410A) was used to generate the modulated signal with a 1.3 $\mathrm{GHz}$ carrier frequency. Fig. 8 shows the output spectrum for several drain-source voltages $(0,0.4$, and 0.6 volts) for $5 \mathrm{dBm}$ LO power. The measured ACPR is improved more than $15 \mathrm{~dB}$ when the transistor is slightly positive biased at its drain terminal. The best ACPR value was found for 0.6 volts of $V_{d s}$, which agrees quite well with the minimum level for $3 \mathrm{f}_{\mathrm{IF}}$, as is shown in Fig. 6.

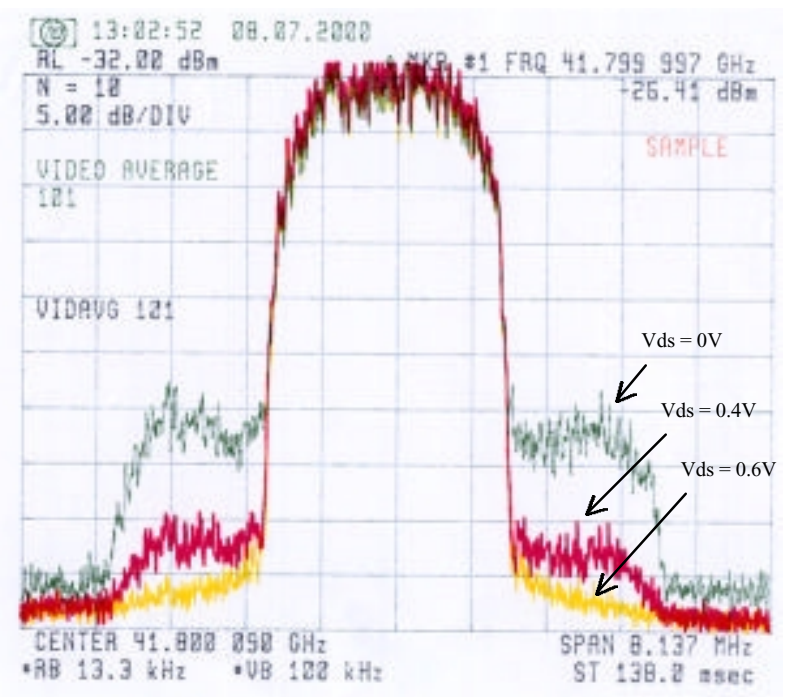

Fig. 8: QPSK signal output spectrum for several $\mathrm{V}_{\mathrm{ds}}$ values

\section{CONCLUSIONS}

A resistive monolithic Q-band HEMT mixer has been designed and measured. Minimum conversion loss of $10 \mathrm{~dB}$ was measured in the $40.8-49 \mathrm{GHz}$ frequency band. The circuit has been designed for optimum conversion loss and IMD performance using transistor two-sided harmonic measurements across $\mathrm{V}_{\mathrm{ds}}$ and $\mathrm{V}_{\mathrm{gs}}$. Minimum IMD performance was measured near the predicted sweet spots. This result agrees with a $15 \mathrm{~dB}$ spectral regrowth reduction for a digital QPSK signal for the same $V_{\mathrm{ds}}$ value.

\section{ACKNOLEDGEMENTS}

This work has been supported by the CICYT, Project $n^{\circ}$ IFD1997-1769-C04-02/ESP and $n^{\circ}$ TIC971129-C04-01.

\section{REFERENCES}

[1] S. A. Maas, "A GaAs MESFET Mixer with very Low Intermodulation" IEEE Trans. Microwave Theory Tech. , vol. 35, pp. 425-429, Apr 1987

[2] S.A. Maas, "The RF and Microwave Circuit Design Cookbook". Norwood, MA: Artech House, 1998.

[3] J.Pedro and J. Pérez, "Accurate simulation of GaAs MESFET intermodulation distortion using a new drainsoruce current model". IEEE Trans. Microwave Theory Tech, vol. 42, pp25-33, Jan.1994.

[4] J.A. García, J.C. Pedro, M.L. de la Fuente, N.B. Carvalho, A. Mediavilla, A. Tazón, "Resistive FET Mixer Conversion Loss and IMD Optimization by Selective Drain Bias”. IEEE MTT-S Digest. pp 803-806, June 1999.

[5] J.A. García, J.C. Pedro, N.B. Carvalho, A. Mediavilla, A. Tazón, "Accurate nonlinear resistive FET modeling for IMD calculations", in $28^{\text {th }}$ european Microwave Conf., pp. 272-276, 1998.

[6] J.A. García, J.C. Pedro, M.L. de la Fuente, N.B. Carvalho, A. Mediavilla, A. Tazón, "Resistive FET Mixer Conversion Loss and IMD Optimization by Selective Drain Bias”. IEEE Trans. on Microwave Theory and Techniques, vol. 47.no.12, pp 2382-2392, December 1999. 